\title{
Análisis DOFA al quehacer ecuménico en Colombia: una aproximación en perspectiva teológica y estratégica*
}

\author{
Gustavo Adolfo Gallardo Oliveros**
}

Recibido: 15 de enero de 2014 • Aprobado: 24 de marzo de 2014

\section{Resumen}

El ecumenismo, como movimiento que atrae conciencias, proyectos y esfuerzos a gran escala, viene a significar en nuestros días una constante en la teología y eclesiología católicas con perspectivas ad intra y ad extra. Si hay que hablar de herencias del Concilio Vaticano II, una de estas es precisamente la nota ecuménica que tiene. Por tal razón, este artículo se propone realizar una aproximación en perspectiva teológica y estratégica al quehacer ecuménico en Colombia a través de un sencillo análisis DOFA, herramienta que permite revisar elementos tanto internos como externos del fenómeno ecuménico y sus alcances desde la aparición de los resultados de Vaticano II hasta nuestros días. ¿Cómo ha sido la comprensión y aceptación de las propuestas ecuménicas en Colombia a partir del Concilio?, ¿cuáles son los antecedentes que alimentan dicha experiencia?, ¿quiénes sus protagonistas?, ¿existen propuestas de fácil acceso y materialidad en cuestiones ecuménicas? Estas son algunas de las cuestiones a las que este ejercicio intentará responder.

Palabras Clave: teología, ecumenismo, iglesias, análisis DOFA, estrategia, Colombia.

* El presente artículo es resultado de investigación del autor.

** Licenciado en Administración de Empresas de la Universidad del Zulia, Maracaibo, Venezuela, Estudios filosóficos en el Instituto de Teología para Religiosos, Caracas, Venezuela, Estudios teológicos en la Universidad Santo Tomás de Aquino de Bogotá y en la Universidad Pontificia Bolivariana de Medellín. Fraile de la Orden de Predicadores de la Provincia de Venezuela. Correo electrónico: gusdominic@gmail.com 


\title{
SWOT analysis to ecumenical task \\ in Colombia: An approach in theological \\ and strategic perspective
}

\begin{abstract}
Ecumenism, as a movement that attracts consciousness, projects and large-scale efforts, comes to mean nowadays a constant in Catholic theology and ecclesiology with ad intra and ad extra perspectives. If we must speak about the legacies of the Second Vatican Council, one of these is precisely the ecumenical touch it has. For this reason, this article tries to make an approach in theological and strategic perspective to the ecumenical task in Colombia through a simple SWOT analysis, tool that enables to review both internal and external elements of the ecumenical phenomenon and its scope since the appearance of the results of Vatican II until today. How has the understanding and acceptance of ecumenical proposals been in Colombia since the Council?, what are the backgrounds that feed such experience?, who are its chief actors?, are there proposals of easy access and materiality in ecumenical matters? These are some of the questions this exercise will try to answer.
\end{abstract}

Keywords: theology, ecumenism, churches, SWOT analysis, strategy, Colombia.

\section{Analyse DOFA de l'oeuvre oecuménique en Colombie: Une approche dans une perspective théologique et stratégique}

\begin{abstract}
Comme le mouvement qui attire des consciences, des projets et des efforts à grande échelle, l'oecumenisme vient à signifier dans nos jours une constante dans la théologie et ecclésiologie catholiques avec des perspectives ad intra et ad extra. S'il faut parler des hérédité du Concile du Vatican II, l'une d'elles est précisément la note oecuménique qu'elle a. Pour cette raison, cet article se propose de réaliser une approche dans une perspective théologique et stratégique a l'oeuvre oecuménique en Colombie à travers d'une d'analyses simples DOFA, outils qui permet de réviser des éléments tant internes comme externes du phénomène oecuménique et de ses portées depuis l'apparition des résultats du Vatican II, à nos jours. Comment c'est passée la compréhension et l'acceptation des propositions oecuméniques en Colombie à partir du Concile ?: Quels sont les antécédents qui alimentent la-dite expérience ?: Qui en sont les protagonistes ?: Existent-il, des propositions facile
\end{abstract}


d'accès ainsi que de la matérialité dans des questions oecuméniques? Ce sont certaines des questions auxquelles cet exercice essaiera de répondre.

Mots-clés: Théologie, oecuménisme, Eglise, analyse DOFA, stratégie, Colombie..

\section{Introducción}

La pregunta por la situación actual del movimiento ecuménico en Colombia surge, en primer lugar, debido a las exigencias que plantea la eclesiología que tiene sus raíces en el Concilio vaticano $\mathrm{II}^{1}$ y la atractiva tendencia del papa Francisco basada en la teología del encuentro y la asistencia a las periferias de la existencia humana ${ }^{2}$. Uno de los mayores incentivos de dicho acontecimiento es, sin duda alguna, la promoción de la unidad entre todos los cristianos, en la que uno de los principales documentos, la Lumen Gentium $\left(L G^{3}\right)$, que trata básicamente de la constitución de la Iglesia (lo que es la Iglesia) y que fue aprobado el 21 de noviembre de 1964, es el diseño de una reingeniería eclesial ad intra y ad extra. En dicha jornada fueron aprobados otros dos documentos importantes para este tema: el decreto Orientalium ecclesiarum, sobre las Iglesias católicas orientales, y el de Unitatis redintegratio, sobre el ecumenismo. Lo expuesto atrae la atención ya que es una demostración de la gran preocupación del Concilio por la unidad de todos los cristianos. Además del cambio de mirada sobre la concepción de sí misma, la Iglesia buscaba una nueva forma de relacionarse con las Iglesias hermanas, que, en gran medida, es un trabajo incompleto en la actualidad.

1 Es evidente que uno de los elementos novedosos resultantes del Concilio es el tinte ecuménico que el traspira.

2 En su reciente visita al Brasil, en el marco de la celebración de la Jornada Mundial de la Juventud, el papa Francisco manifestaba la necesidad del encuentro como primer escalafón para lograr una evangelización de impacto.

3 La constitución dogmática Lumen Gentium es el intento de responder a la pregunta hacia la Iglesia: ¿qué dices de ti misma? Es una especie de reingeniería eclesial donde el trasfondo es el aggiornamento o actualización que pretendió en su tiempo el papa Juan XXIII. Era necesario que la Iglesia se actualizara en cuestiones planteadas por la sociedad de la época y la sociedad actual. La constitución dogmática Lumen Gentium se vuelve el tronco del Concilio y presenta, en el campo de la eclesiología, una auténtica revolución; el ecumenismo se deja entrever en sus líneas, no escapa a tales pretensiones, sino que por el contrario ilumina teológicamente hablando los resultados alcanzados. 
En segundo lugar, la pregunta por la situación del ecumenismo en Colombia es fundamental en tiempos actuales gracias a la necesidad de buscar y encontrar vías de contemplación y acción que den alternativas a un hombre sin piso, sin principios sólidos y duraderos, sin una ética para el bien común y no el desenfrenado individualismo. Es evidente que el hombre no se reduce a las dimensiones sociales, culturales, políticas y geográficas. Sea reconocido o no, el ser humano lee la realidad muy frecuentemente desde lo religioso, incluso sin darse cuenta o hacerse consciente de ello. La pregunta es ipuede hacer algo el movimiento ecuménico frente a fenómenos actuales?, o ¿acaso los peritos en ecumenismo solo reducen su trabajo a una mesa y un papel? Son múltiples las situaciones en las que el movimiento ecuménico en Colombia puede actuar.

Una de ellas, que acá ocupa el tercer lugar, es el tan famoso contexto de los diálogos de paz. Para nadie es un secreto que la Iglesia Católica en Colombia es conservadora, incluso para temas tan trascendentales como el de la promoción de la paz. No desestimo la labor realizada por un reconocido obispo dominico en las jornadas de peregrinación con la imagen de Nuestra Señora de Chiquinquirá por el río Magdalena ${ }^{4}$, ni más faltaba. Pero qué enriquecedor sería que varias iglesias cristianas se unieran y multiplicaran esfuerzos y estrategias para tal promoción. ¿Cuál ha sido el impedimento? ¿Acaso una arraigada intolerancia que hunde sus raíces en tiempos pasados? En este ejercicio se intentará iluminar dicha coyuntura. Es necesario, teológicamente hablando, mirar la manera de cómo ha permeado a la realidad colombiana el dinamismo ecuménico en sus diferentes versiones. Para esto el método que se propone acá es señalar, desde el punto de vista teológico y estratégico, un análisis al estilo DOFA 5 .

4 Desde el sábado 7 de septiembre de 2013, más de 130 frailes dominicos de la provincia de San Luis Bertrán de Colombia recorrieron con una réplica de la imagen de Nuestra Señora de Chiquinquirá, 54 jurisdicciones arquidiócesanas y diocesanas del territorio nacional, en una jornada mariana nacional por la familia, la reconciliación y la paz. Desde el 16 de septiembre monseñor fr. Jorge Leonardo Gómez Serna, O. P., fr. Gerardo Aguilar Colmenares, O. P., fr. Ernesto José Mora Arias, O. P. y otros frailes del Convento de Chiquinquirá recorrieron 52 puertos ubicados al lado y lado del río Magdalena.

$5 \quad$ El análisis DOFA es una herramienta de diagnóstico y análisis para la generación creativa de posibles estrategias a partir de la identificación de los factores internos y externos de una organización, fenómeno o situación concreta, dada una actual situación y contexto. Consiste en identificar los elementos que tienen el mayor potencial para un mayor desarrollo y mejora, que permiten minimizar los impactos negativos del contexto. El nombre es un acrónimo de las iniciales de los factores analizados: debilidades, oportunidades, fortalezas y amenazas. En primer lugar se identifican los cuatro componentes del análisis, divididos en los aspectos internos que corresponden a las fortalezas y las debilidades, y los aspectos externos o del contexto, que corresponden a las oportunidades y las amenazas. Confrontar Shapiro (2004). 


\section{Fundamentos del ecumenismo a gran escala}

\section{Una mirada al pasado para seguir construyendo el futuro desde acciones presentes}

El significado del término ecumenismo no es de fácil detección y comprensión si de definiciones exactas se trata, sobre todo si este se analiza como parte fundamental del quehacer teológico actual dadas las complejas realidades que el mundo enfrenta. Lamentablemente, en cuestión de material bibliográfico con tintes latinoamericanos, no se cuenta con una variada gama de posibilidades. No obstante en Latinoamérica, específicamente en Colombia, sí se cuenta con un grupo muy selecto de sacerdotes, religiosos y organizaciones que han apostado por hacer del ecumenismo una ventana abierta al quehacer teológico-pastoral en la nación.

Un caso concreto de este fenómeno es el aporte de un excelente especialista en la latería: Fray Carlos Mario Alzate Montes, O. P. ${ }^{6}$ Según Alzate Montes, el término ecumenismo pertenece a una familia de palabras (del griego clásico), relacionadas con términos que tienen que ver con la vivienda, el asentamiento, la permanencia. Este teólogo propone algunos términos-raíz de dicha familia lingüística:

- Oikos: con los significados de casa, vivienda, habitación, pueblo.

- Oikeiotês: con los significados de relación, emparentado, amistad.

- Oikeiow: que expresa habitar, cohabitar, reconciliarse, estar familiarizado

- Oikonomeô: que expresa administración, encargo, responsabilidad de la casa

- Oikoumene: cuyo significado es tierra habitada, mundo conocido y civilizado, universo

Según el especialista, la raíz primera de la que provienen los otros términos es oikos (casa, lugar donde se mora, espacio habitable y habitado). La palabra oikoumene, de la que procede directamente ecumenismo significará, consecuentemente, el mundo habitado en el que coexisten diversos pueblos, con diversidad de lenguas y culturas. Pero en su sentido primero sería la "tierra habitada por los

6 Fray Carlos Mario Alzate Montes, O. P. Fraile Dominico, rector general de la Universidad Santo Tomás, protagonista del quehacer ecuménico en Colombia. 
helenos", es decir, por un pueblo civilizado que ofrece una cultura abierta a todos, dando esa unidad básica de cosmovisión que exige una civilización auténtica ${ }^{7}$.

Alzate Montes, tras la búsqueda de una comprensión del término en cuestión, hace un recorrido de gran valor, para dar luces y matices a lo propuesto ${ }^{8}$ :

1. Roma aportará, después, una perspectiva política y la Pax romana será el símbolo de la oikoumene, es decir de todos los pueblos que aceptan vivir bajo la influencia del "mundo civilizado", que viene a identificarse con el Imperio Romano.

2. El término oikoumene aparece también en la literatura bíblica. En el Nuevo Testamento se emplea en quince ocasiones, en algunas de las cuales recupera el viejo sentido de mundo (Hch 11, 28 Biblia de Jerusalén) o de Imperio Romano (Lc 2, 1). En la Carta a los Hebreos $(2,5)$ se pone especial énfasis en el carácter transitorio de la presente oikoumene, para afirmar con fuerza la inminente llegada de una nueva y transformada, regida directamente por Jesucristo.

3. La palabra oikoumene, desde una perspectiva neotestamentaria, parece que debe entenderse como un proceso en continuo desarrollo que inicialmente refiere a la "tierra habitada", que va haciéndose un "lugar habitable", la casa en la que cabe toda la familia humana y cuya realidad no se encierra en la frontera inminente de la historia. La respuesta del hombre en esta tierra, ante la llamada de Dios, es como el germen de una nueva oikoumene, que viene como obra de Dios pero con la colaboración humana.

4. En el cristianismo primitivo el término oikoumene - siguiendo la trayectoria bíblica - es usado en las acepciones ya conocidas: mundo, Imperio Romano, mundo civilizado, etc. Así, por ejemplo, el autor del Martirio de Policarpo (un escrito del siglo II) se refiere varias veces en su escrito a "la Iglesia Católica extendida por la oikoumene". La palabra se introduce en el lenguaje eclesiástico oficial cuando el Concilio de Constantinopla

7 De ahí que oikoumene llegará a entenderse como el "mundo habitado" hasta donde se extendía la influencia griega, porque más allá es el mundo de los bárbaros... Las perspectivas geográfica y cultural, entrelazadas, aparecen como el significado primero de la palabra ecumenismo.

8 Provincia San Luís Bertrán de Colombia. Studium Generale San Alberto Magno. Curso de Ecumenismo: apuntes y propuestas. Fray Carlos Mario Alzate Montes, O. P. 
(381) denomina al Concilio de Nicea - celebrado en el 325- como Concilio ecuménico. Desde ese momento el término ecuménico va a designar aquellas doctrinas y usos eclesiales que son aceptados como norma autoritativa y con validez universal en toda la Iglesia Católica.

5. Con la caída del Imperio Romano, apunta Alzate Montes, la palabra deja de tener obviamente connotaciones políticas y pasa a tener ya con exclusividad un sentido exclusivamente eclesiástico: la oikoumene es la Iglesia Universal. Tres grandes hombres de Iglesia serán designados doctores ecuménicos: Basilio el Grande, Gregorio Nacianceno y Juan Crisóstomo. A partir de ahí se emplea para designar los concilios que hablan en nombre de toda la Iglesia. Más tarde, la palabra se aplica también a los grandes credos de la antigua Iglesia, y así son llamados credos ecuménicos los de los apóstoles, el de Nicea y el de san Atanasio.

6. Durante el siglo XIX aparece un nuevo significado que, con el tiempo, tendrá la acepción técnica moderna. Alzate Montes hace mención a que en 1846 se instituye en Londres una alianza evangélica, con el fin de preparar un concilio ecuménico evangélico universal. Sus participantes pertenecen a diferentes denominaciones. En la clausura de aquel encuentro, el pastor calvinista francés Adolphe Monod agradecía a los organizadores británicos "el fervor de su piedad" y el "espíritu verdaderamente ecuménico" que habían demostrado. Visser't Hooft ha recordado que aquella expresión del pastor francés "parece haber sido la primera cita consignada respecto del uso de la palabra para indicar una actitud más que un hecho[...]" (2004, p. 738).

7. Pero el uso del término en la acepción recordada no goza todavía de una aceptación universal, advierte Alzate Montes. Así, por ejemplo, en 1900 se celebra en la ciudad de Nueva York una "conferencia ecuménica misionera". Los organizadores dejan muy claro que han aceptado ese calificativo porque se han propuesto un plan de expansión misionera que "abarque toda la tierra". La acepción común continúa siendo la del primitivo sentido geográfico, universal. Poco después, en la famosa Conferencia Misionera Mundial de Edimburgo (1910), el título de ecuménica es eliminado, pues la ausencia de las Iglesias Ortodoxas y Católica - según sus organizadores - hace inapropiado su uso.

8. Los movimientos Fe y Constitución y Vida y Acción van a suponer un drástico cambio en el significado del término ecumenismo. El arzobispo 
luterano Nathan Söderblom durante la Primera Guerra Mundial sugiere la creación de una reunión internacional de Iglesias con el apelativo de ecuménica, para intentar resolver el problema de la guerra. Propone la puesta en marcha de una especie de consejo ecuménico de las Iglesias. Su idea, no obstante, solo tomará cuerpo varios decenios después. Pero la palabra adquiere ya una nueva acepción: la relación amistosa entre Iglesias con la finalidad de promover la paz internacional, de tratar de la unión de varias Iglesias o incluso de generar el espíritu de acercamiento entre cristianos de diversas confesiones.

9. A partir de la Conferencia de Oxford (1937), el término ecuménico designa, ya con toda claridad, las relaciones amistosas entre las diferentes Iglesias con el expreso deseo de realizar la "una sancta" y de estrechar la comunión entre todos los creyentes de Jesucristo. Tras la fundación del Consejo Ecuménico de las Iglesias - en el mundo anglosajón prefieren referirse a este como Consejo Mundial de Iglesias - en Amsterdam (1948), el término ecuménico expresa ya sin duda alguna el intento de reconciliación de las Iglesias cristianas como expresión visible de la universalidad del cristianismo y como un signo para que el mundo crea.

Habiendo reflexionado y comprendido lo anterior, Alzate Montes concluye que a las primeras acepciones de tipo geográfico, cultural y político, se añade después la referencia a la Iglesia, tanto la Iglesia Universal, extendida por todo el universo, como más tarde al interés por la tarea misionera y al deseo inequívoco de unidad cristiana que se extiende por las distintas Iglesias separadas durante siglos.

\section{La invitación al ecumenismo en Jesucristo evangelio vivo}

Son múltiples los teólogos y especialistas que a nivel internacional han escrito sobre el ecumenismo con aportes interesantes, sin embargo la fuente más genuina para iluminar la realidad ecuménica de ayer y de hoy son los evangelios, $\mathrm{y}$, en su interior, el mismo Cristo como fundamento de la iglesia. Cristo motiva a todo cristiano con la plegaria que dirige al Padre, en la que pide que todos los creyentes vivan en la unidad de la fe, siendo todos uno, como él y el Padre son uno (Jn 17, 21ss). Ese deseo de Cristo viene a significar para la Iglesia una herencia y misión a la que hay que apostar. Para mantener su fidelidad a la voluntad del Señor, la Iglesia emprende animosamente la tarea de buscar y mantener la unidad de todos los cristianos. Esto señala para la Iglesia dos grandes objetivos 
útiles para el análisis DOFA propuesto al inicio. Uno está dirigido hacia dentro: la superación de las divisiones entre cristianos, que se expresa en el restablecimiento del llamado a la unidad, santidad y apostolicidad, que son elementos que señalan los aspectos esenciales de la identidad cristiana. El otro se dirige hacia afuera: la búsqueda de entendimiento universal con las culturas, razas, religiones e ideologías sobre aquellas tareas, cuestiones y situaciones que afectan profundamente a la humanidad, pues el anuncio de la cercanía del reino que predicó Jesús implicaba desde su origen un anuncio de salvación y un llamado a la unidad para toda persona. En este sentido, se puede afirmar que Jesús no es cabeza solo de la Iglesia, sino también de toda la humanidad. La Iglesia, con su testimonio de vida y misión, hace visible en este mundo la promesa de salvación que Jesús trae a $\operatorname{todos}^{9}$ (Ratzinger, 1982, p. 211; ).

Junto al deseo por mantener la unidad como nota esencial de la vocación cristiana y signo inconfundible de su elección como pueblo de Dios, el ecumenismo expresa también el deseo que tiene la Iglesia Católica y las demás confesiones cristianas por seguir comprometidas en el anuncio de la verdad y mantiene un carácter de constante renovación dentro de la comunidad eclesial. Por esta razón, se reitera constantemente dentro de la tarea ecuménica la necesidad de mantener una actitud de diálogo, a través del cual no solo se puede llegar a superar prejuicios y aclarar controversias, sino enriquecer las multiformes manifestaciones de los dones y carismas con los que el Señor ha bendecido a su Iglesia y que van revelando nuevos ámbitos en los que se puede establecer una cooperación conjunta y solidaria para la ayuda de las personas que lo necesiten. Por otro lado, no cabe duda de que el diálogo en la tarea ecuménica permite adquirir un conocimiento más auténtico y un aprecio más justo de la doctrina y de la vida de cada comunidad eclesial.

Con lo anterior, se deja entrever otra de las características esenciales del ecumenismo: su responsabilidad misionera. No cabe duda de que el trabajo en búsqueda de la unidad es un camino por el cual la Iglesia cumple su misión en el mundo y expresa concretamente su catolicidad. En esta situación actual, en la que los conflictos ensangrientan al mundo, la Iglesia está llamada a ser signo

9 J. Ratzinger, Theologische Prinzipienlehre, Münich 1982, p. 211.; W. Kasper, Der Gott Jesu Chirsti, Mainz 1982, p. 21. Peter Neuner, Ökumenische Theologie.Darmstadt 2005, p. 15ss. Jörg Urban. Handbuch der Ökumenik Vol. I, II y III.Paderborn 1987; Andreas Karrer, Bekenntnis und Ökumene. Göttingen 1996, p. 11-95. Peter Lüning, Ökumene der kleinen Schritte. Regensburg 2010, p.26ss. 35s.; Karl Rahner y Herber Vorgrimler, Kleines Konzilskompendium. Freiburg 2008 (1966), p.217ss. 
e instrumento de la unidad y de la reconciliación con Dios y entre los hombres. Una vez superadas las diferencias puede mostrarse la iglesia como imagen creíble y anuncio de la buena nueva del evangelio convincente. Solo cuando los cristianos estén en condición de dar un testimonio en la unidad del mensaje de la salvación en su enseñanza y en sus prácticas pueden llegar a ser signo creíble de esperanza para el mundo entero.

La tarea ecuménica implica para el cristianismo tres aspectos muy importantes. El primero es la tarea de conservar su propia identidad y su unidad predicando el evangelio único de Cristo en las más diversas culturas, sin que se pierda la fuerza originaria que lo constituye como fuente y fundamento de la unidad y de la identidad cristiana. El segundo aspecto tiene que ver con la forma en que la comunidad cristiana aborda - evitando una postura polémica y defensiva - el tema de la elección, que se indica al considerar el cristianismo como heredero de las promesas que Dios ha dado desde antiguo y como verdadera comunidad que se constituye como pueblo de Dios. El tercer aspecto es el tema de la comprensión de la unidad dogmática en la que se intenta restablecer la unidad de la Iglesia.

Todos estos aspectos, que expresan la dimensión que tiene la tarea ecuménica de la Iglesia, hablan de la responsabilidad que la Iglesia tiene con vistas a alcanzar la unidad.

El decreto Unitatis Redintegratio expresa así la esencia de la función que el ecumenismo debe desarrollar en la vida y el práctica de la Iglesia:

Promover la restauración de la unidad entre todos los cristianos es uno de los fines principales que se ha propuesto el Sacrosanto Concilio Vaticano II, puesto que única es la Iglesia fundada por Cristo Señor, aun cuando son muchas las comuniones cristianas que se presentan a los hombres como la herencia de Jesucristo; todos se confiesan discípulos del Señor, pero sienten de modo distinto y siguen caminos diferentes, como si Cristo mismo estuviera dividido. División que abiertamente repugna a la voluntad de Cristo y es piedra de escándalo para el mundo y obstáculo para la causa de la difusión del Evangelio por todo el mundo.

De esta forma, se exhorta a mantener una participación activa en todo aquello que favorezca el compromiso que la tarea ecuménica trae consigo como imperativo de una conciencia cristiana que se halla guiada por fe y por la caridad. Así pues, no se trata de una tarea para especialistas. Todos los cristianos están 
llamados a participar de muy diversas maneras, especialmente a través la oración, por la cual se hace propio el deseo del Señor de que todos los cristianos vivan en la unidad en la que Cristo vive con el Padre. Esto también se logra alejando de si actitudes y modos de actuar que dañan el deseo de alcanzar y lograr la unidad.

\section{Aspectos esenciales del llamado al ecumenismo}

En la reflexión en torno al ecumenismo sobresalen como notas características las siguientes, que recogen la dimensión de la oración y santidad de los cristianos como exigencia primera para ir en dirección a la unidad: los compromisos y las acciones pastorales que impulsan este caminar, y el compromiso de anunciar con palabras y con obras la imagen de Dios, que es relevada y encarnada en Jesucristo.

\section{La plegaria misma de Jesús para que todos sean uno (Jn 17, 20, 21)}

La Iglesia se presenta como sacramento e instrumento de la unión deseada entre los cristianos, esto es entre toda la humanidad con Cristo. Con este deseo de Jesucristo, la unidad adquiere el significativo valor de convertirse en aspecto esencial de la vocación cristiana. La unidad es de igual manera la cumbre de la oración sacerdotal de Jesucristo, que es ciertamente el testamento de su amor. De este modo, la unidad hace parte de la esencia de la Iglesia también como comunidad de amor. Así, la unidad expresa la voluntad de Dios manifestada desde tiempo antiguo, como manifiesta a la vez la voluntad de Cristo para que esta unidad sea signo de credibilidad para el mundo.

\section{Llamados a vivir en la unidad que da el Espíritu mediante el vínculo de la paz (Ef 4, 1-6; 1 Co 12, 12-13; Col 3, 12-15)}

El Directorio para la aplicación de los principios y normas sobre el ecumenismo del Pontificio Consejo para la promoción de la unidad de los cristianos señala que:

el movimiento ecuménico pretende ser una respuesta al don de la gracia de Dios, que llama a todos los cristianos a la fe en el misterio de la Iglesia, según el designio de Dios que desea conducir a la humanidad a la salvación y a la unidad en Cristo por el Espíritu Santo. Este 
movimiento los llama a la esperanza de que se realice plenamente la oración de Jesús: 'que todos sean uno'. Los llama a esta caridad que es el mandamiento nuevo de Cristo y el don por el que el Espíritu Santo une a todos los fieles. El Concilio Vaticano II pidió claramente a los católicos que extiendan su amor a todos los cristianos, con una caridad que desea superar en la verdad lo que los divide y que se dedica activamente a realizarlo; deben actuar con esperanza y en la oración por la promoción de la unidad de los cristianos, y su fe en el misterio de la Iglesia les estimula e ilumina de tal modo que su acción ecuménica pueda ser inspirada y guiada por una verdadera comprensión de la Iglesia que es 'el sacramento, es decir, a la vez el signo y el medio, de la unión íntima con Dios y de la unidad de todo el género humano'. (1993, p. 9)

\section{Credibilidad del anuncio evangélico como mensaje de reconciliación $(2 \mathrm{Co} 5,18)^{10}$}

Cuando los cristianos viven y rezan juntos del modo descrito en el capítulo IV de la Segunda Carta a los Corintios dan testimonio de la fe que comparten y de su bautismo en el nombre de Dios, padre de todos, en su Hijo Jesús, redentor de todos y en el Espíritu Santo, que transforma y une todas las cosas por la fuerza de su amor. Hay otras muchas formas de colaboración ecuménica, basadas en esta comunión de vida y de dones espirituales, que expresan y favorecen la unidad y resaltan el testimonio que los cristianos dan al mundo del poder salvífico del Evangelio. Al colaborar en favor del estudio y difusión de la Biblia, los estudios litúrgicos, la catequesis y los estudios superiores, la pastoral, la evangelización, en el servicio de caridad en un mundo que lucha por realizar sus ideales de justicia, de paz y de amor, los cristianos llevan a la práctica lo que ha sido propuesto en el decreto sobre el ecumenismo:

Que todos los cristianos confiesen ante las naciones su fe en Dios uno y trino, en el Hijo de Dios encarnado, nuestro Redentor y Señor, y por un esfuerzo común, en la mutua estima, den testimonio de nuestra esperanza que no será confundida. Hoy que se ha instaurado una amplia

10 (Pontificio Consejo, 1993, 161-162). 
colaboración en el plano social, todos los hombres sin excepción están llamados a esta obra común, pero sobre todo los que creen en Dios y muy en primer término, todos los cristianos, a causa precisamente del nombre de Cristo con que se honran. La colaboración de todos los cristianos expresa claramente la unión que ya existe entre ellos, y pone en evidencia más luminosa el rostro de Cristo Servidor. (UR 12)

Los cristianos no pueden cerrar su corazón al clamor de las necesidades del mundo contemporáneo. La contribución que aporten en todos los campos de la vida humana en los que se manifiesta la necesidad de salvación es más eficaz cuando la hacen todos juntos y cuando se ve que están unidos en su realización. Desearán, pues, hacer juntos cuanto les permite su fe. La ausencia de una comunión completa entre las diferentes iglesias y comunidades eclesiales, las divergencias que aún existen en la enseñanza de la fe y de la moral, la memoria herida y la herencia de una historia de separación son elementos que limitan lo que los cristianos pueden hacer juntos ahora. Su colaboración puede ayudarles a superar lo que obstaculiza la plena comunión, a poner en común sus recursos para construir una vida y un servicio cristianos: esto conformaría el testimonio común que se deriva de esto con vistas a la misión que comparten: "En esta unión en el plano de la misión, querida principalmente por el mismo Cristo, todos los cristianos deben descubrir lo que les une incluso antes de que se realice su plena comunión" (RH 12).

\section{La vocación que tiene la iglesia de ser signo e instrumento de la comunión que Dios ha establecido con todas las personas}

Como el Concilio Vaticano II lo recuerda, la Iglesia tiene un solo objetivo: continuar, bajo la guía del Espíritu, la obra misma de Cristo, que vino al mundo a dar testimonio de la verdad, para salvar y no para juzgar, para servir y no para ser servido (GS 3). La Iglesia tiene la gran misión de congregar a todas las personas en la unidad del Señor, por medio del Espíritu, que es el agente primordial de la evangelización y de la congregación de todos en la unidad. La misión de la iglesia es una vocación universal ( $L G 13$ ) que quiere llegar a todas las personas y a todos los pueblos para ofrecer el mensaje de salvación que brinda el Evangelio. 


\section{El "escándalo" de la desunión de los cristianos}

Desde su comienzo, el cristianismo ha tenido que lidiar con tensiones, conflictos y divisiones, para preservar la unidad en la fe y en la práctica. En ninguna época de la historia de la Iglesia aparece esta unidad duradera y totalmente asegurada. Cada nueva generación de cristianos vio como tarea urgente la necesidad de expresar y confesar el sentido ecuménico del mensaje evangélico. La unidad está enraizada en la imagen y realidad trinitaria de Dios. Como misterio de la fe, es esta unidad un don divino. Los errores y el pecado que se presentan en medio de la comunidad cristiana no permiten, sin embargo, que esta unidad logre su realización de manera plena en medio de la Iglesia. De esta forma, estas múltiples divisiones históricas y doctrinales en una pluralidad de iglesias y de comunidades representan un grave obstáculo en el cumplimiento de la voluntad del Señor. La incapacidad o la falta de empeño en dirigir una mirada común en procura de vivir la vocación evangélica a la que los cristianos han sido llamados no permite que se perciba ni se recupere la realidad concreta del amor que nos une en Cristo.

Con esta urgencia por superar el escándalo de la división entre los cristianos, la tarea del diálogo ecuménico, como lo expresa el decreto sobre ecumenismo Unitatis Redintegratio, es promover la restauración de la unidad, y es uno de los fines principales que se ha propuesto el Sacrosanto Concilio Vaticano II, puesto que única es la Iglesia fundada por Cristo Señor, aun cuando son muchas las comuniones cristianas que se presentan a los hombres como la herencia de Jesucristo. Todos se confiesan discípulos del Señor, pero sienten de modo distinto y siguen caminos diferentes, como si Cristo mismo estuviera dividido. Esta división repugna abiertamente a la voluntad de Cristo y es piedra de escándalo para el mundo y obstáculo para la causa de la difusión del Evangelio por todo el mundo (UR 1). Para recuperar la unidad, se ha de mantener el compromiso de que todos y cada uno, según sus posibilidades, promueva y haga posibles las acciones que llevan a la realización del gran deseo de vivir y celebrar la fe en la unidad de los hijos de Dios.

El Directorio para la aplicación de los principios y normas sobre el ecumenismo señala finalmente ${ }^{11}$ que:

el testimonio común dado por todas las formas de colaboración ecuménica es ya misionero. De hecho, el movimiento ecuménico ha caminado

11 N. 205. 
parejo con un redescubrimiento de la naturaleza misionera de la Iglesia por muchas comunidades. La colaboración ecuménica hace ver al mundo que los que creen en Cristo y viven por su Espíritu, habiendo llegado a ser hijos de Dios que es Padre de todos, son capaces de comenzar a superar con valor y esperanza las divisiones humanas, incluso en materias tan delicadas como la fe y la práctica religiosa. Las divisiones que existen entre los cristianos son ciertamente un gran obstáculo para el éxito de la proclamación del Evangelio. Pero los esfuerzos realizados para vencerlas hacen mucho para compensar el escándalo y dar credibilidad a los cristianos que proclaman que Cristo es aquel en quien todas las personas y todas las cosas están unidas

Como evangelizadores debemos ofrecer a los fieles de Cristo, no la imagen de hombres divididos y separados por litigios nada edificantes, sino la de personas maduras en la fe, capaces de encontrarse más allá de las tensiones reales gracias a la búsqueda común, sincera y desinteresada de la verdad. Sí, la suerte de la evangelización está ciertamente unida al testimonio de unidad dado por la Iglesia. Es esta una fuente de responsabilidad, pero también de consuelo. (EN 77) $(1993,205)$

\section{Una luz evangélica}

Las comunidades cristianas fundamentan la importancia de la unidad y del entendimiento entre las diversas confesiones cristianas en el Nuevo Testamento, que aparece como punto de partida y permanece como razón fundamental para la búsqueda de la unidad de los cristianos, gracias a las decisivas y reiteras afirmaciones que apelan a la unidad de los cristianos como pueblo de Dios y como comunidad que está sujeta al evangelio vivo que es Cristo (Ga 1, 6ss; 1, 11; 1, 12; $2,5)$. El texto por excelencia referido al diálogo ecuménico es la oración de despedida presentada por el testimonio del evangelista Juan de "que todos sean uno"12 (Jn 17, 21). La petición por la unidad de todos los creyentes se presenta aquí como uno de los deseos más importantes de Jesús, es el centro mismo de su plegaria, de su proyecto, de su misión. Esta unidad es una de las características esenciales de la comunidad cristiana expuesta en los Hechos de los Apóstoles con magistral

12 Es bueno unificar las citas bíblicas, con una única traducción. 
textura y signo de su elección y carácter como verdadera comunión con el Padre. El evangelista Juan se encarga de fundarla y hacerla visible en el ser mismo de Dios. El autor sagrado intenta expresar no solo el deseo de Jesús de convocar a todos como a un solo rebaño (Jn 10, 4ss), sino el compromiso que adquiere de dar su vida, no solo por el rebaño de Israel sino por todos aquellos que han reconocido su voz y le han seguido (Jn 11, 52).

Por su parte, el evangelio de Lucas posee para el ecumenismo un gran significado. Desde el relato mismo del nacimiento (Lc 2,1), se presenta a Jesús y a su mensaje como una buena nueva que convoca a todos los pueblos, sin discriminarlos, y los llama en la búsqueda de la verdad (Lc 4, 43; 8, 1). En el Evangelio de Lucas, la predicación de Jesús sobre el reinado de Dios tiene un claro significado universal, viene como anuncio y juicio de liberación para todos los pueblos que habían caído bajo la dominación del Maligno (Lc 4, 5; 17, 26; Ap 12, 9). Congregados como un solo pueblo, se conecta la misión mesiánica de Jesús con el sufrimiento de un pueblo sometido al sufrimiento (Lc 4, 18), y se considera a todo ser humano, sin importar su origen, como digno de la acción salvadora de Dios, tal como se expresa en el pasaje del criado del centurión romano (Lc 7, 1-10).

El Evangelio de Mateo expresa claramente la misión de ir "por todas las naciones" a hacer discípulos de Jesús (Mt 28, 19; Mc 16, 14-18; Lc 24, 36ss; Jn $20,19-23)$ para que aprendan, guarden la enseñanza del evangelio y vivan permaneciendo en Cristo. No se trata tan solo de que todas las naciones se sientan convocadas a vivir bajo la alianza de Dios, se trata a la vez, de que los discípulos vayan por todo el mundo haciendo discípulos de Cristo. No sin razón se suele denominar el evangelio de Mateo, como el evangelio ecuménico.

En el de Marcos esta misión de ir predicar la llegada del reino es una tarea que no admite prórrogas. Un corazón generoso y entregado junto a una fe total en ese acontecer de Dios en la historia son los puntos característicos de la visión que tiene Marcos del anuncio. La perspectiva universal del mensaje que Jesús trae se abre paso de una forma dramática en el Evangelio de Marcos (Mc 7, 24, 30): el evangelio no es solo dado para los "hijos de Israel", sino que es anuncio y liberación mesiánica para todos aquellos que tengan fe en él. Ahora, el Dios de Israel se ha convertido en el Dios de todas las naciones, de todos aquellos que ponen su confianza en él. Esta es una de las novedades más radicales y que revisten de gran trascendencia como principio para constituir un verdadero sólido ecumenismo. Los evangelios presentan la buena nueva del Evangelio como un anuncio de la bondad y la justicia de Dios que no establece diferencia entre las personas. 
Junto a los textos evangélicos, vale la pena resaltar otros textos neotestamentarios, que a la luz de la predicación de Jesús, resaltan el valor que tiene la búsqueda de la unidad dentro de la comunidad cristiana. En la Carta a los Efesios (específicamente, Ef 4, 4-6; 2, 11-22) se funda el ecumenismo de una manera muy clara sobre la naturaleza trinitaria de Dios, y en la que la unidad en la fe y el bautismo son elementos esenciales para la realización de la unidad eclesial y para la conformación de un solo cuerpo y un solo espíritu en Cristo. El versículo 12 de la primera carta Corintios es un importante reconocimiento de la unidad en medio de la diversidad y de los multiformes dones del Espíri$\mathrm{tu}$, porque la diversidad no es algo que se tenga por accidental en la vida de la comunidad cristiana, sino que es un aspecto de su catolicidad y de su múltiple forma de servir. El cuerpo no está formado por una sola parte, sino por muchas y estas necesitan del cuerpo, y estas conforman una comunidad que, como el mismo texto lo señala, no quiere decir en modo alguno uniformidad. Para la teología del Nuevo Testamento en general se sobreentiende que la Iglesia, en su carácter esencial, está llamada a ser una, pero que se reconoce en cada una de las comunidades locales y en la reunión de estas (Hch 15, 22; 1Co 11, 18; 14, 4ss; 16, 19; Col 4, 15).

\section{Antecedentes ecuménicos en colombia: fortalezas y debilidades}

Teniendo como trasfondo el conflicto ecuménico que a lo largo de los años ha reinado en Colombia por causas no solo doctrinales, sino también políticas y culturales, y en donde la desconfianza ha sido el punto de partida ante los intentos de diálogo que hasta ahora se han gestado, hablar de ecumenismo en Colombia es ante todo hablar (en palabras del pastor luterano Jairo Suárez, de la comunidad luterana San Pablo de Tunjuelito, Bogotá) de la recuperación de confianzas, para así compartir experiencias de convivencia y de fe.

Cabe destacar que en Colombia surgió una organización, alrededor de los años cuarenta, que procuraba la defensa de los aun llamados evangélicos ante las agresiones de los católicos. Su nombre era CEDEC. Una de las diferencias del ecumenismo en Colombia fue que no recibió influencia del movimiento ecuménico mundial, por el estilo de iglesias que han llegado al país. Es conveniente resaltar que el movimiento ecuménico organizado tiene antecedentes en la actividad 
del conde de Zinzendorf ${ }^{13}$. A renglón seguido hubo otro intento de iglesias protestantes reunidas en un congreso en Edimburgo en el año 1910. Allí se acordó delimitar los sitios estratégicos para la acción misionera y la propagación de ideal cristiano. Los sitios privilegiados fueron África y América, pero, para Latinoamérica no hubo estrategia misionera, ya que se consideraba que las Américas eran territorio cristianizado por las tropas españolas, influenciadas por la Iglesia Católica Romana.

Como reacción las Iglesias Protestantes Latinoamericanas se reunieron en Panamá en 1915 y decidieron utilizar el modelo de Edimburgo aplicado a la realidad de las Américas. Paralelamente nace un movimiento motivado por el fundamentalismo y el movimiento pentecostal ${ }^{14}$, que, por esos tiempos, no tenía la suficiente organización y solidez. Este factor permite que misioneros norteamericanos le apuesten al propósito acordado en Panamá y comienzan a dividirse la zona. Tal signo hace que la Iglesia Católica Romana (asumiendo características estatales) reaccione ante la presencia de otros cultos cristianos ${ }^{15}$.

Cabe destacar que la Iglesia Católica de este contexto, por ser estatal, se torna elitista, alejada de la realidad del país, lo que hizo que sustentara muchas acciones de guerra con la bendición de las armas ${ }^{16}$. Caso homólogo ocurrió en Venezuela, Argentina y en términos generales en aquel contexto latinoamericano. La iglesia Católica recurre al Estado en busca de apoyo para contrarrestar la acción de las iglesias evangélicas advenedizas de cualquier denominación, incluyendo las históricas; con esto, se estableció que la única religión válida era la Católica: todo lo que se saliera de este conglomerado era considerado evangélico sin importar la especificidad de la comunidad; además era visto como nocivo. Este fenómeno tiene antecedentes en lo que se denomina patria boba, es decir, cuando gobernaba un liberal las iglesias no católicas tenían más posibilidades de predicación y expansión que cuando el gobernante era conservador. Razón

13 Nicolaus Ludwig Von Zinzendorf fue un luterano alemán que quiso compartir su fe con otras denominaciones evangélicas y católicas en el centro de Europa. A este se considera como uno de los primeros antecedentes del proyecto ecuménico mundial.

14 Este movimiento tiene dos focos de origen: Belén de Pará (Brasil) y Lousiana (EE.UU).

15 Dentro de este contexto, vale destacar que bajo la sombrilla del ecumenismo, se encuentran todas las Iglesias que consideran que Cristo es el Señor: católicos, ortodoxos, luteranos, menonitas, baptistas, entre otros. Por esta razón, el diálogo con otras iglesias se torna diferente.

16 Este argumento se puede sustentar a partir de la historia de Colombia y en la influencia de los movimientos independentistas. 
por la cual se pude afirmar que la Iglesia Católica Colombiana es una de las más conservadoras de América.

\section{Las primeras realidades tocadas: el campo}

La primera población que atrae a los llamados evangélicos es el campesinado, cuyos miembros encontraron un cierto apoyo para lograr un acercamiento al gobierno y expresar inquietudes ante sus necesidades. Los grupos evangélicos delegaron voceros que servían de puente entre el campesinado y el Estado, nombrando organizaciones muy insipientes, entre ellas CEDEC. En 1950 se reúnen para enfrentar la crisis de violencia desatada luego de la muerte del líder político Jorge Eliecer Gaitán. El gobierno y la Iglesia asumen que quien se autodenomina liberal estaba estrechamente asociado a denominaciones evangélicas y era además perteneciente a la masonería. Este ambiente de discriminación hundía sus raíces en antecedentes que permeaban incluso celebraciones litúrgicas, lo que motivó a sacerdotes a usar el espacio de la homilía o sermón para propiciar en sus feligreses el ataque verbal y corporal a los llamados evangélicos; más aún, se conoce un canto litúrgico de la primera mitad del siglo XIX, que incitaba el rechazo a los evangélicos. A la par del aumento de la persecución a los campesinos evangélicos asociados con los liberales, en dicha época eran asesinados indiscriminadamente liberales y evangélicos. Son múltiples los casos en los cuales se asesinaba a una persona o familia por el solo hecho de confesarse evangélica ${ }^{17}$.

\section{Entre heridas y rencores}

Este panorama violento y opresor ocasionó en muchos cristianos evangélicos heridas significativas y profundas. Aunque la comunidad Luterana de San Pablo - por voz de su pastor Jairo Suárez - se reconoce como Iglesia Cristiana Evangélica Católica, él mismo señala que la historia refiere a hechos desagradables de rencor e intolerancia por parte de actores católicos en contra de familias protestantes afectadas, siendo a estas se les quemaba las viviendas o se les asesinaba a miembros de su familia. No obstante, este escenario no apagó el deseo ecuménico

17 Se cuenta con testimonio de una familia luterana venida del norte de Boyacá, que sufrió esta persecución y tuvo que desplazarse a Bogotá, aparte de otros casos en los cuales los hijos de los luteranos eran rechazados de la educación oficial y sus casas eran incineradas y sus tierras expropiadas. Esos sucesos ocurrieron alrededor de los años cincuenta y sesenta. 
en el contexto, por lo cual, entre los años cincuenta y sesenta surge la iniciativa de diálogo entre las iglesias con más apertura y el Estado, esto a raíz del nacimiento de una organización llamada Cedecol ${ }^{18}$ (Consejo Evangélico de Colombia), cuya misión inicial fue solicitar al Estado las garantías pertinentes para que las iglesias evangélicas contaran con la libertad ciudadana de reunirse y celebrar su fe. Sin embargo, el Estado siguió fiel al concordato ${ }^{19}$ que desde hacía años había trazado con la Santa Sede, complicando más el asunto de ser evangélico.

En dicho panorama hablar de ecumenismo era casi imposible. Se cuenta una anécdota según la cual los curas párrocos incitaban a sus feligreses a reaccionar ante la presencia de los evangélicos cerrando las puertas de sus casas o incluso lanzándoles piedras para que abandonaran el lugar. No obstante, a partir de la Constitución de 1991, el panorama se torna cambiante esto gracias a la libertad de expresión religiosa contemplada en ella con peso constitucional. Dichas iglesias, especialmente en las zonas rurales, cuentan entonces con los derechos para asistir y manifestar su fe sin ningún tipo de agresión, aunque actualmente persisten vicios de intolerancia que impiden la convivencia ecuménica.

\section{Resultados prematuros pero significativos}

Si bien el movimiento ecuménico en Colombia ha despertado, dicho despertar ha sido muy incipiente, debido a que la realidad no ha sido enriquecida por la

18 La historia de Cedecol está ligada desde su inicio a la historia de los evangélicos en Colombia y a la historia misma de Colombia. Nació durante la crisis de la llamada violencia de los años cincuenta. Por esa razón, es casi imposible deslindar para Cedecol una historia propia que no sea influenciada por el devenir de las iglesias y los vaivenes de la historia política del país. Desde 1929 cuando apenas existían cuatro denominaciones en Colombia, hubo interés en reunirse para dialogar sobre la forma más efectiva de llevar a cabo el cumplimiento de la misión en Colombia, siguieron otras realizadas en Palmira, Armenia y en 1939 en Bogotá se llevó a cabo una de las más importantes reuniones, porque congregó a doce denominaciones. Los días 21 al 25 de junio de 1950 se reunió en Bogotá, la Asamblea Constituyente de la Confederación Evangélica de Colombia (CEDEC), con la participación de 40 delegados en representación de 19 denominaciones. En esta oportunidad se elaboró una constitución y una confesión de fe, que fueron aprobadas y luego sometidas. Tomado de: http://cedecol.net/historia-cedecol/, septiembre 22 de 2013, 3:00 pm.

19 La República de Colombia y la Santa Sede con el propósito de asegurar una fecunda colaboración para el mayor bien de la Nación colombiana, animados por el deseo de tener en cuenta las nuevas circunstancias que habían ocurrido tanto para la Iglesia Católica, Apostólica y Romana como para la República de Colombia desde 1887, fecha del concordato suscrito entre estas, habían determinado celebrar un nuevo concordato (1973), que constituía la norma que regularía en lo sucesivo, sobre bases de recíproca deferencia y mutuo respeto, las relaciones entre la Iglesia Católica y el Estado. 
presencia de organizaciones ecuménicas mundiales (como por ejemplo el Consejo Mundial de Iglesias o el Consejo Latinoamericano de Iglesias), contrario a lo alcanzado en otros países como Brasil. Otra razón es que la presencia de los grupos promotores del diálogo ecuménico en Colombia es minoritaria.

Todo lo anterior es fundamento para plantear dos niveles frente al intento de ecumenismo colombiano. El primero es el ecumenismo institucionalizado o de cabezas de iglesias (Iglesia Católica, Iglesia Luterana, Iglesia Presbiteriana, la Iglesia Baptista, la Iglesia Metodista, la Iglesia Anglicana, la Iglesia Ortodoxa y otras de corte pentecostal), el cual se basa en reuniones, encuentros y asambleas, pero que muchas veces no toca las realidades de las comunidades eclesiales. El segundo es el ecumenismo de comunidades de base, o en lenguaje católico, el ecumenismo parroquial, el cual es tan deficiente que sigue inmerso en la intolerancia y el irrespeto.

En ecumenismo en Colombia es un "ecumenismo de escritos y discursos bonitos", pero que no logra bajar a la conciencia de los creyentes que conviven con otros individuos que siguen al mismo Cristo por caminos diferentes. Es un ecumenismo centrado en la sabana de Bogotá, muchas veces desconectado del ecumenismo paisa o del ecumenismo caleño. Paralelamente, hay otro diálogo ecuménico que se desarrolla entre iglesias evangélicas, las cuales se han organizado bajo la figura de Cedecol (que reúne casi el $75 \%$ de las iglesias de todo el país), la red ecuménica de Colombia en la que comparten espacios algunas comunidades religiosas femeninas y otras que persiguen fines sociales puntuales (como la promoción del diálogo por la paz, el conflicto armado, entre otros frentes).

El movimiento ecuménico en Colombia debería aprovechar los espacios que se suscitan en las problemáticas coyunturales colombianas, subsanando las molestias y heridas del pasado para juntos construir la casa del Señor.

En definitiva, el ecumenismo en Colombia pide agritos sustentos como la confianza, el respeto y la meta clara que está en Cristo.

\section{Estrategias ecuménicas: oportunidades y amenazas}

En Colombia han sido múltiples los esfuerzos por hacer de la dinámica ecuménica uno de los motores que impulse en el país la puesta en práctica del espíritu de Vaticano II. Las propuestas se han originado en el seno de la Conferencia Episcopal Colombiana (CEC), en la que se hace un gran esfuerzo por tal cometido, y han logrado permear universidades importantes, actores sociales destacados y 
organizaciones que buscan un objetivo común: la preservación y respeto de la dignidad humana.

\section{El ecumenismo desde la academia: Diplomado para la promoción de la unidad de los cristianos}

La Universidad Pontificia Bolivariana, en conjunto con la Conferencia Episcopal Colombiana, en su afán por servir a la sociedad y a la Iglesia en sus caminos de evangelización, reconciliación y paz, ha promovido en varias ocasiones la formación permanente de obispos, sacerdotes, consagrados y laicos en temas de ecumenismo y diálogo interreligioso a través de nuevas tecnologías. Esta se constituye como una oportunidad para impulsar el encuentro de unidad a fin fortalecer el testimonio de fraternidad, de forma que se proteja la dignidad humana y la promoción de los derechos humanos.

Es válido destacar que la Iglesia Católica Colombiana ha venido adelantando puentes de acercamiento con las otras confesiones religiosas presentes en el país, particularmente las iglesias históricas para adelantar en conjunto jornadas de oración y compromiso solidario. También ha desarrollado actividades de acercamiento a otras grandes religiones, en las que se destacó el encuentro con la comunidad judía. Todas estas iniciativas potenciadas como una vía para aportar a la reconstrucción nacional desde el mutuo compromiso con el Dios de la vida y la caridad (Conferencia Episcopal Colombiana, 2012).

Son muchos los llamados magisteriales y exhortaciones pontificias a iniciar y sostener diálogos fraternos ecuménicos. A estos llamados, la Conferencia Episcopal de Colombia y la Universidad Pontificia Bolivariana están dispuestas a darles respuesta desde su riqueza axiológica, sus experiencias desarrolladas y el crecimiento de los hermanos y hermanas colombianos. Con este propósito se puede encontrar también un aliado en el ITEPAL-CELAM, interesados en promover y divulgar una formación para el diálogo ecuménico. Esto, sin duda alguna, enriquece la experiencia ecuménica de la nación.

Para los actores involucrados en esta iniciativa, la unidad en el diálogo sigue siendo un desafío del Evangelio y un llamado permanente de Nuestro Señor Jesucristo para anunciarlo desde la fraternidad en medio de las naciones. Pero este fin no puede quedarse en un propósito de buena voluntad, sino que requiere una preparación de agentes de pastoral para el diálogo desde una fundamentación bíblica, magisterial y pastoral que haga posible el encuentro respetuoso y 
productivo en los campos eclesiales, sociales, diocesanos, comunitarios, medios de comunicación y en particular en los escenarios educativos.

Para lograr estos fines y sus aplicaciones, es importante unir los esfuerzos académicos de formación continua. Este propósito se encuentra en coherencia con las palabras del beato Juan Pablo II, quien las testimonió con su vida:

Donde existe la voluntad sincera de seguir a Cristo, el Espíritu infunde con frecuencia su gracia en formas diversas de las ordinarias. La experiencia ecuménica nos ha permitido comprenderlo mejor. Si en el espacio espiritual interior que he descrito las comunidades saben verdaderamente 'convertirse' a la búsqueda de la comunión plena y visible, Dios hará por ellas lo que ha hecho por sus santos. Hará superar los obstáculos heredados del pasado y las guiará, por sus caminos, a donde él quiere: a la koinonia visible que al mismo tiempo es alabanza de su gloria y servicio a su designio de salvación.

Esta conversión del corazón y santidad de vida, juntamente con las oraciones privadas y públicas por la unidad de los cristianos, han de considerarse como el alma de todo el movimiento ecuménico, y con razón puede llamarse ecumenismo espiritual. (UUS 84)

La propuesta de diplomado está en coherencia con el propósito del Consejo Pontificio para la unidad de los cristianos que recomienda:

Las Conferencias episcopales regionales o nacionales, en colaboración con las otras Iglesias y Comunidades eclesiales, así como con los Consejos de las Iglesias, podrían constituir grupos destinados a dar una expresión común a los valores cristianos y humanos fundamentales. Esta especie de discernimiento realizado en común ayudaría a proporcionar un importante punto de partida para abordar ecuménicamente cuestiones de naturaleza social y ética; esto desarrollaría la dimensión moral y social de la comunión parcial de que ya gozan los cristianos de las diversas Iglesias y Comunidades eclesiales. (Pontificio Consejo, 1993, 214).

La formación ecuménica trata de que todos los cristianos estén animados por el espíritu ecuménico, sean las que fueren su misión y su función particulares en el mundo y en la sociedad. En la vida del fiel, lleno del Espíritu de Cristo, tiene importancia primordial el don implorado 
por Cristo antes de su Pasión, es decir, la gracia de la unidad. (Pontificio Consejo, 1993, 58)

El Directorio para la aplicación de los principios y normas sobre el Ecumenismo permite pensar diferentes escenarios en los cuales un diplomado tendría utilidad:

- La familia, llamada "iglesia doméstica” por el Concilio Vaticano II, es el primer lugar en que a diario se construye o debilita la unidad por el encuentro de personas, diferentes en muchos aspectos, pero que se aceptan en una comunión de amor; ahí se ha de vigilar también para no mantener prejuicios, sino al contrario buscar en todo la verdad.

- La parroquia, como unidad eclesial reunida en torno a la Eucaris $\neg$ tía, debe ser y proclamarse el lugar del auténtico testimonio ecuménico. Uno de los grandes deberes de la parroquia es, en consecuencia, el de educara sus miembros en el espíritu ecuménico. Esto exige una cuidadosa atención a los contenidos y a las formas de predicación, sobre todo de la homilía, y también de la catequesis.

- La escuela, de cualquier orden o nivel, debe dar una dimensión ecuménica a su enseñanza religiosa, y tender según su forma propia, a la formación del corazón y de la inteligencia en los valores humanos y religiosos, educando para el diálogo, para la paz y las relaciones interpersonales

- Los grupos, asociaciones y movimientos eclesiales. La vida cristiana, y de modo especial la vida de las iglesias particulares, se ha ido enriqueciendo a lo largo de la historia con una variedad de expresiones, proyectos, espiritualidades, según los carismas dados por el Espíritu para la edificación de la Iglesia, manifestándose una neta distinción de tareas al servicio de la comunidad.

En la posible construcción de un evento académico se consideran los aportes de los miembros de las iglesias históricas e instituciones pertenecientes al comité ecuménico de la Conferencia Episcopal de Colombia bajo la coordinación de esta última y con el respaldo académico de la Universidad Pontificia Bolivariana y una eventual participación del Instituto Teológico Pastoral para América Latina. Esta construcción fraterna es una prueba de que es posible trabajar en conjunto inspirados por el espíritu ecuménico. 


\section{¿Es de impacto una acción como esta?}

El documento Ut Unum Sint de Juan Pablo II se alegra de que las conferencias episcopales hayan constituido comisiones especiales para la promoción del espíritu y de la acción ecuménicos que aplican las orientaciones conciliares de Vaticano II (UUS 23). La Conferencia Episcopal de Colombia no dejó escapar esta oportunidad y, en coherencia con sus planes estratégicos y servicio pastoral al país, le apostó en su momento a este reto. Además, se pone de manifiesto que las iglesias particulares se encuentran en sus territorios con la presencia de otras iglesias y comunidades eclesiales compartiendo características espirituales, étnicas, políticas y culturales comunes; en consecuencia, se aplica también para Colombia el que:

Una Iglesia Católica particular, o varias iglesias particulares que actúan estrechamente unidas, pueden hallarse en situación muy favorable para tomar contacto a este nivel con otras iglesias o comunidades eclesiales. Aquellas pueden establecer con estas relaciones ecuménicas fructíferas, beneficiosas para el movimiento ecuménico más amplias. (Pontificio Consejo, 1993, 37, 38).

Promover desde el nivel episcopal espacios de diálogo ecuménico se presenta como un llamado con mucha responsabilidad, como lo manifiesta el Código de derecho canónico ${ }^{20}$.

Como un aporte y en respuesta a dichos retos es necesario un diplomado para la preparación de agentes de pastoral, con el fin de poner en práctica lo propuesto en el Directorio para la aplicación de los principios y normas sobre el ecumenismo del Pontificio Consejo para la promoción de la Unidad de los Cristianos en su numeral 47:

a. poner en práctica las normas e instrucciones de la Santa Sede en la materia;

20 El Código de derecho canónico para la Iglesia latina (755) afirma:

$\S 1$. Corresponde en primer lugar al Colegio episcopal entero y a la Sede Apostólica animar y dirigir entre los católicos el movimiento ecuménico cuyo objetivo es restablecer la unidad entre todos los cristianos, unidad que la Iglesia, por voluntad de Cristo, está obligada a promover.

$\S 2$. Corresponde igualmente a los Obispos y, según el derecho, a las Conferencias episcopales, promover esta misma unidad, y dar reglas prácticas, según las diferentes necesidades y ocasiones favorables, teniendo en cuenta las disposiciones emanadas de la suprema autoridad de la Iglesia. 
b. aconsejar y asistir a los obispos que creen una comisión ecuménica en su diócesis, y estimular la cooperación entre los responsables diocesanos de ecumenismo y entre las comisiones mismas, organizando, por ejemplo, encuentros periódicos de delegados y representantes de las comisiones diocesanas;

c. animar y ayudar donde convenga a las otras comisiones de la conferencia episcopal y de los sínodos de las Iglesias orientales católicas a tener en cuenta la dimensión ecuménica del trabajo de dicha conferencia, de sus declaraciones públicas, etc.;

d. promover la colaboración entre los cristianos, por ejemplo aportando ayuda espiritual y material donde sea posible, a la vez a las organizaciones ecuménicas existentes y a los proyectos ecuménicos a promover en el ámbito de la enseñanza y la investigación, o en el de la pastoral y la profundización de la vida cristiana, según los principios del decreto conciliar sobre ecumenismo, en sus nos. 9 I2;

e. establecer consultas y diálogos con los dirigentes eclesiásticos y con los consejos de las Iglesias existentes a nivel nacional o territorial (diferentes de la diócesis) y crear estructuras adaptadas a estos diálogos;

f. designar expertos, con mandato oficial de la Iglesia, para participar en las consultas y en el diálogo con los expertos de las Iglesias, de las Comunidades eclesiales y organizaciones antes mencionadas;

g. mantener contactos y colaboración activa con las estructuras ecuménicas establecidas por los institutos de vida consagrada y las sociedades de vida apostólica, y con las de otras organizaciones católicas, dentro de su territorio;

h. organizar el intercambio de observadores e invitados con ocasión de asambleas eclesiales importantes y de otros eventos de este género, a nivel nacional o territorial;

i. informar a los obispos de la Conferencia y de los sínodos sobre el desarrollo de los diálogos que se tienen en su territorio; compartir estas informaciones con el Pontificio Consejo para la Promoción de la Unidad de los Cristianos de Roma, de modo que el mutuo intercambio de pareceres y experiencias y los resultados del diálogo puedan promover otros diálogos a diversos niveles de la vida de la Iglesia, y 
j. en general, mantener relaciones entre los sínodos de las Iglesias orientales católicas o las conferencias episcopales en lo referente a las cuestiones ecuménicas, y el Pontificio Consejo para la Promoción de la Unidad de los Cristianos, en Roma, así como con las comisiones ecuménicas de otras Conferencias territoriales.

\section{¿Cuales son sus ejes trasversales?}

\section{A. Compromiso comunitario}

El modelo de la comunidad-comunión deseada por Jesús y buscada por el movimiento ecuménico solo es posible en la vida Trinitaria "porque cuanto más se unan en estrecha comunión con el Padre, con el Verbo y con el Espíritu, tanto más íntima y fácilmente podrán acrecentar la mutua hermandad" (UR 7).

Juan Pablo II recuerda que el movimiento ecuménico es fruto de una comunidad que vive los valores teologales, que "asume con esperanza la acción ecuménica como un imperativo de la conciencia cristiana iluminada por la fe y guiada por la caridad" (UUS 8).

En la medida que demos testimonio como iglesias de la centralidad de la comunidad Trinitaria reconoceremos en nosotros que es posible la convivencia y el amor nacido de la unidad en la diversidad.

Más aun, tanto la CEC como la UPB tienen claro que en el documento de Aparecida se afirma con esperanza que:

La comprensión y la práctica de la Eclesiología de comunión nos conduce al diálogo ecuménico. La relación con los hermanos y hermanas bautizados de otras Iglesias y comunidades eclesiales es un camino irrenunciable para el discípulo y misionero, pues la falta de unidad representa un escándalo, un pecado y un atraso al cumplimiento del deseo de Cristo. (CELAM, 2007, 227)

\section{Compromiso dialogal}

El Pontificio Consejo para la Promoción de la Unidad de los Cristianos describe con los siguientes términos las características del diálogo ecuménico $(1993,172)$, que también se aplicaron al diplomado: 
- El diálogo está en el corazón mismo de la colaboración ecuménica y la acompaña en todas sus formas.

- $\quad$ Este diálogo pide que se escuche y se responda, que se trate de comprender y de hacerse comprender.

- $\quad$ Es estar dispuesto a plantear cuestiones y a ser, a su vez, interrogado.

- Es comunicar algo propio y tener confianza en lo que los demás dicen de sí mismos.

- Cada interlocutor debe estar dispuesto a dar siempre más aclaraciones y a modificar sus puntos de vista personales y sus modos de vivir y de actuar, dejándose guiar por el amor auténtico de la verdad.

- La reciprocidad y el compromiso mutuo, así como el sentimiento de que los interlocutores están todos en pie de igualdad, son elementos esenciales del diálogo.

- $\quad$ El diálogo ecuménico permite a los miembros de las diversas iglesias y comunidades eclesiales llegar a conocerse entre sí, a identificar los temas de fe y de práctica que tienen en común y los puntos en que difieren.

- Tratan de comprender las raíces de estas diferencias y valorar en qué medida constituyen un obstáculo real a una fe común.

- Cuando reconocen que las diferencias constituyen una barrera real a la comunión, tratan de hallar los medios para superarlas a la luz de esos puntos de la fe que tienen ya en común.

\section{Compromiso fundado en el amor fraterno}

El amor tiene su modelo en Cristo: "Ámense los unos a los otros como yo los he amado" (Jn 15, 12). Se hace creíble en el testimonio de hermandad en la que nos reconocerán como sus discípulos (Jn 13,34). Lo contrario al amor entre los cristianos es el más grande escándalo para el mundo.

En apremiantes palabras de Juan Pablo II, abanderado del diálogo ecuménico se encuentra que:

El amor es artífice de comunión entre las personas y entre las Comunidades. Si nos amamos, es más profunda nuestra comunión, y se orienta 
hacia la perfección. El amor se dirige a Dios como fuente perfecta de comunión - la unidad del Padre, del Hijo y del Espíritu Santo-, para encontrar la fuerza de suscitar esta misma comunión entre las personas y entre las Comunidades, o de restablecerla entre los cristianos aún divididos. El amor es la corriente profundísima que da vida e infunde vigor al proceso hacia la unidad. (UUS 21)

Continuando con el documento Ut Unum Sint, se invita a reconocer que sin amor y humildad es imposible la comunión entre cristianos que supere las dificultades y diferencias nacidas de la cultura, la sociedad, la psicología, la teología (UUS 36). Vaticano II pide extender el amor a todos los cristianos para que la verdad supere las divisiones y pide con imperativo a todos los miembros de la Iglesia ser sacramento en la misma línea de lo propuesto por Lumen Gentium como signo y medio de la unión con Dios y también de la unidad de todo el género humano (Pontificio Concilio, 1993, 9).

\section{Compromiso misionero}

En la realidad de nuestro continente y su necesidad de ser evangelizada, pide de los creyentes en Cristo "nuevas formas de discipulado y misión en la comunión" (CELAM, 2007, 232-233), que preparen para la conversión y el anuncio. La congregación para la doctrina de la Fe recuerda que:

La Iglesia no es una realidad replegada sobre sí misma, sino permanentemente abierta a la dinámica misionera y ecuménica, pues ha sido enviada al mundo para anunciar y testimoniar, actualizar y extender el misterio de comunión que la constituye: a reunir a todos y a todo en Cristo; a ser para todos 'sacramento inseparable de uni-

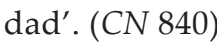

El Pontificio Consejo para la promoción de la unidad de los cristianos insiste en que toda colaboración ecuménica es de por sí misionera pues demuestra al mundo que los llamados en Cristo, hijos de Dios que es Padre universal, son capaces de superar sus divisiones y el escándalo consecuente. Esta es la mejor forma de "dar credibilidad a los cristianos que proclaman que Cristo es Aquel en quien todas las personas y todas las cosas están unidas" (Pontificio, 1993, 205). 


\section{Compromiso participativo}

Unitatis Redintegratio llama a todos los miembros eclesiales a ser corresponsables del diálogo ecuménico y la unidad en Dios:

El empeño por el restablecimiento de la unión corresponde a la Iglesia entera, afecta tanto a los fieles como a los pastores, a cada uno según su propio valor, ya en la vida cristiana diaria, ya en las investigaciones teológicas e históricas. Este interés manifiesta la unión fraterna existente ya de alguna manera entre todos los cristianos, y conduce a la plena y perfecta unidad, según la benevolencia de Dios. (CN 205)

El mismo llamado al compromiso se hace en Aparecida a todos los ministros ordenados, al laicado, a los religiosos y religiosas para trabajar en ecumenismo en los "diversos campos de la vida eclesial, pastoral y social" (CELAM, $2007,232)$.

\section{¿Dónde se aplicaría?}

\section{Promoción del estudio bíblico en conjunto}

El documento Unitatis Redintegratio reconoce el que estudio bíblico es un instrumento precioso "en la mano poderosa de Dios para lograr aquella unidad que el Salvador presenta a todos los hombres" (UR 21). El diplomado ofreció herramientas para promover el encuentro y reconocimiento entre grupos de colectivos ecuménicos de estudios bíblicos que entre sus funciones pueden apoyar la preparación de la semana de oración por la unidad de los cristianos y congresos bíblicos ecuménicos.

\section{Acompañamiento a una espiritualidad ecuménica}

En esta línea de acción ecuménica espiritual que llama a los cristianos a la santidad y que se convierte en núcleo del movimiento ecuménico se pueden enmarcar las siguientes actividades de egresados del diplomado:

- Promover oraciones ecuménicas en las celebraciones particulares de cada iglesia. 
- Seguir apoyando la celebración de la Semana de Oración por la Unidad de los Cristianos ${ }^{21}$.

- Celebrar la memoria de un martirologio común contemporáneo ${ }^{22}$.

- Crear una red permanente de oración ecuménica por la paz, el perdón y la justicia ${ }^{23}$.

- Aprovechar la red virtual para el acompañamiento espiritual ecuménico a través de un chat, una página, una comunidad virtual y un centro de documentación ecuménica virtual.

\section{Animar el trabajo solidario}

Cada comunidad eclesial, en nombre de Cristo, debería realizar acciones evangélicas de solidaridad y compromiso con los hermanos más desfavorecidos pero estas acciones aparecen en muchas ocasiones atomizadas. El diplomado dio herramientas a los agentes de pastoral a promover la integración de proyectos coordinados y colaborativos entre las iglesias, lo cual permitiría un mayor impacto y un mejor aprovechamiento de experiencias, recursos y personas.

21 Quienes se identifican profundamente con Cristo deben configurarse con su oración, en especial a su oración por la unidad; quienes viven en el Espíritu deben dejarse transformar por el amor que, por la causa de la unidad, "lo soporta todo, lo cree todo, lo espera todo, lo aguanta todo"; quienes viven en espíritu de arrepentimiento serán particularmente sensibles al pecado de las divisiones y pedirán por el perdón y la conversión. Quienes buscan la santidad serán capaces de reconocer sus frutos fuera también de los límites visibles de su Iglesia. Serán llevados a conocer realmente a Dios como el único capaz de congregar a todos en la unidad, porque es el Padre de todos (Pontificio Consejo, 1993, 25).

22 Si nos ponemos ante Dios, nosotros cristianos tenemos ya un Martirologio común. Este incluye también a los mártires de nuestro siglo, más numerosos de lo que se piensa, y muestra cómo, en un nivel profundo, Dios mantiene entre los bautizados la comunión en la exigencia suprema de la fe, manifestada con el sacrifico de su vida (UUS 84).

23 A los católicos y a los otros cristianos se les recomienda la oración en común para presentar juntos a Dios las necesidades y preocupaciones que comparten - por ejemplo la paz, las cuestiones sociales, la caridad mutua entre los hombres, la dignidad de la familia, los efectos de la pobreza, el hambre y la violencia, etc. - . Semejantes a estos casos son las ocasiones en que, según las circunstancias, una nación, una región o una comunidad desean dar gracias a Dios comunitariamente o pedir su ayuda; lo mismo en un día de fiesta nacional, en tiempo de calamidad o duelo públicos, en el día fijado para celebrar el recuerdo de los muertos por la patria, etc. Se recomienda también esta oración común en las reuniones donde se juntan los cristianos para el estudio o la acción (Pontificio Consejo, 1993, 109). 
En palabras de Ut Unum Sint:

Sucede cada vez más que los responsables de las comunidades cristianas adoptan conjuntamente posiciones, en nombre de Cristo, sobre problemas importantes que afectan a la vocación humana, la libertad, la justicia, la paz y el futuro del mundo. Obrando así comulgan con uno de los elementos constitutivos de la misión cristiana: recordar a la sociedad, de un modo realista, la voluntad de Dios, haciendo ver a las autoridades y a los ciudadanos el peligro de seguir caminos que llevarían a la violación de los derechos humanos. Es claro, y la experiencia lo demuestra, que en algunas circunstancias la voz común de los cristianos tiene más impacto que una voz aislada. (UUS 43)

En conclusión, dicha iniciativa persiguió y sigue apostándole al ofrecimiento de herramientas teológicas, bíblicas, históricas y los referentes magisteriales requeridos para desarrollar diálogos y trabajos conjuntos en el campo ecuménico. Todo esto se da para analizar el origen y evolución del movimiento ecuménico, interpretar los componentes, posibilidades y dificultades del diálogo ecuménico, conocer la historia, desarrollo y características de las iglesias históricas e identificar las condiciones para adelantar iniciativas de diálogo ecuménico a nivel espiritual, académico, social o eclesial con las familias cristianas anglicana, luterana, metodista, menonita, bautista, ortodoxa y presbiteriana.

\section{Conclusión}

Para nadie es un secreto que el ecumenismo se ha convertido en una respuesta a los signos de los tiempos, y dicha respuesta cada vez es más vigente, tanto para la Iglesia occidental como la oriental, y la Iglesia Latinoamericana debe jugar su papel dentro de tal dinámica. Afortunadamente la presencia nuevos medios de comunicación y de transporte permiten que los individuos estén más cerca unos de otros; las naciones y los pueblos estén relacionados entre sí de forma mucho más estrecha. Ante tal escenario, el ecumenismo viene a representar una de las prioridades de la acción pastoral de la Iglesia Católica y especialmente del papa actual, quien se ha mostrado dispuesto al diálogo ecuménico con teorías y con hechos.

Es muy lamentable señalar que tras la fase del movimiento ecuménico posterior al Concilio Vaticano II (caracterizada por cierta euforia), a lo largo de la 
última década se han experimentado signos de cansancio, decepción y estancamiento, y Colombia no escapa de ello. Hay quienes incluso hablan de una crisis o de un nuevo invierno ecuménico. Sin embargo, ante tales señales de oscuridad se levanta una luz. Han sido grandes los esfuerzos por parte de la Conferencia Episcopal Colombiana, específicamente de fray Mario Rafael Toro Puerta, OFM, director del Departamento de la Promoción de la Unidad y del Diálogo y de varias universidades muy reconocidas en el campo teológico y pastoral de la nación. Se ofrecen propuestas de diplomados, proyectos a largo plazo relacionados con el tema, aporte del movimiento ecuménico en los procesos de paz y toda solución que rescate la dignidad de los colombianos vulnerados y maltratados. ¿Cuál es el problema? La secuela exagerada del ser conservador que se ventila en la mayor parte de los militantes católicos.

Para otros, el gran problema del ecumenismo en Colombia radica en los interrogantes actuales acerca de la identidad. Ante las preguntas "¿quiénes somos?", “¿quién soy yo?", nadie quiere acabar absorbido por un conjunto anónimo y sin rostro. La cuestión de la identidad se plantea en los individuos así como en las culturas, en los grupos étnicos y en las religiones; se plantea finalmente dentro de las iglesias cristianas, en las que una comprensión equivocada del ecumenismo ha conducido en ocasiones al relativismo y al indiferentismo. Solo unas iglesias con la misma cabeza (Cristo) e identidad definida pueden emprender un diálogo sin miedo a perder con esto su identidad. Por lo tanto, a lo largo de los últimos años han vuelto a surgir cuestiones relacionadas con los fundamentos teológicos y eclesiales de un sano diálogo y de un sano ecumenismo. En Colombia se debe seguir promoviendo esto.

Finalmente, en el ámbito del movimiento ecuménico la cuestión no es solo la conversión de los demás, sino la conversión de todos a Jesucristo. Sin miedo a nada hay que decir que los católicos deben estar dispuestos a hacer un examen de conciencia así como a la autocrítica y al arrepentimiento. Sin esta actitud, el ecumenismo nunca se logrará. Cuando el hombre se acerca más a Jesucristo, en él se acercan más los unos a los otros. No se trata pues de debates sobre política eclesial ni de acuerdos, tampoco se trata de una especie de unión, sino de un camino que, partiendo de una comunión que ya existe pero que todavía es imperfecta, va hacia la comunión plena; de un crecimiento espiritual en la fe y en el amor; de un mutuo intercambio espiritual y de un mutuo enriquecimiento, conocimiento y reconocimiento. 


\section{Referencias}

Alzate, C. M. (2010). Curso de Ecumenismo: apuntes y propuestas. Provincia San Luís Bertrán de Colombia: Provincia San Luis Beltrán.

Celam. (2007). V Conferencia General del Episcopado Latinoamericano y del Caribe.

Conferencia Episcopal Colombiana. (2012). Actas (Vol. II).

Constitución Apostólica. [CIC]. Código de Derecho Canónico para la Iglesia latina.

Concilio Vaticano II. [LG] Constitución sobre la iglesia Lumen Gentium.

Concilio Vaticano II. [UR] Decreto Unitatis redintegratio.

Congregación para la doctrina de la fe. (1992). [CN] Carta Communionis notio.

Juan Pablo II. (1995). [UUS] Encíclica Ut unum sint, sobre el empeño ecuménico

Juan Pablo II. (1979). [RH] Carta Encíclica Redemptor Hominis.

Kasper, W. La Teología Ecuménica: Situación actual. (n.d.). Recuperado en noviembre 25, 2014 de http://es.catholic.net/op/articulos/19331/la-teologia-ecumenicasituacion-actual.htmlPontificio Consejo. (1993). Directorio: para la aplicación de los principios y normas sobre el ecumenismo.

Ratzinger, J. (1982). Theologische Prinzipienlehre: Bausteine zur Fundamentaltheologie. Münich: Wewel.

Shapiro, J. (2004). Herramientas de planificación estratégica. Recuperado de www.civicus. org/new/media/Planificacion\%20strategica.pdf

Visser't Hooft, W. A. (1967). The Word 'Ecumenical': Its History and Use. En R.Rouse y Stephen Neill (Eds.), A History of the Ecumenical Movement (1517-1948). Londres: SPCK. 